\title{
NOTAS SOBRE A ARTE DE GRAMMATICA, LATINA, PORTUGUEZA, BENEDICTINA (LISBOA, 1636) DE FRUTUOSO PEREIRA
}

Rogelio Ponce de León Romeo*

Resumo: Este trabalho analisa diversos aspetos da Arte de grammatica, latina, portugueza, benedictina (Lisboa, 1636) de Frutuoso Pereira; nomeadamente problemas que têm a ver com a tradição textual e com a autoria, bem como questões relacionadas com o enquadramento da referida obra no contexto pedagógico português da primeira metade do século XVII. Também é analisado o enquadramento da Arte de gramatica nas correntes de gramática vigentes na época; em concreto, na gramática racionalista e na gramática escolar.

Palavras-chave: Frutuoso Pereira. Historiografia gramatical. Século XVII.

\section{CONSIDERAÇÕES INICIAIS}

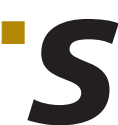

ão bem conhecidas pelos especialistas na historiografia linguística do Português as profundas alterações que se sentiram, no Portugal da primeira metade do século XVII, na configuração teórica e pedagógica de certos textos metagramaticais. No plano da teoria gramatical, pode afirmar-se que as Artes mais inovadores acolheram um conjunto de procedimentos de explicação dos factos linguísticos, integrados naquilo que se tem vindo a designar como gramática racionalista. No contexto português - tal como, de resto, noutras nações europeias -, os manuais gramaticais cuja teoria se configura em torno desta corrente seguem muito de perto a doutrina racionalista defendida pelo humanista espanhol Francisco Sánchez de las Brozas nas suas obras gramaticais que descrevem e versam sobre o Latim; especialmente, na sua Minerua seu de causis de linguae latinae (Salamanca, 1587). Com efeito, na gramaticografia do Português e na latino-portuguesa, casos bem conhecidos de manuais que se servem, em maior ou menor medida, da doutrina sanctiana para a descrição gramatical são a Arte de grammatica pera em breve saber latim (Lisboa, 
1610) de Pedro Sanches (FERNANDES, 2002b; PONCE DE LEÓN, 2002, p. 499-507; PONCE DE LEÓN; ASSUNÇÃO; FERNANDES, 2008) e as obras gramaticais de Amaro de Roboredo: a Verdadeira grammatica latina pera se bem saber em breve tempo (Lisboa, 1615), o Methodo grammatical para todas as linguas (Lisboa, 1619) e a Grammatica latina. Mais breve, e facil que as publicadas até agora na qual precedem os exemplos aas regras (Lisboa, 1625) (SCHÄFER-PRIESS, 1990; KOSSARIK, 1997; FERNANDES, 2002a; PONCE DE LEÓN, 2002, p. 508-520; FERNANDES; ASSUNÇÃO, 2007; PONCE DE LEÓN, 2009).

Por outro lado, num plano mais estritamente didático - mas com claras repercussões na descrição gramatical -, os autores acima referidos - e outros coevos -, acolhendo os avanços desenvolvidos, nessa área, na Europa (PONCE DE LEÓN, 1996, p. 218; FERNANDES, 2002b, p. 61-73), sentiram a necessidade de subverter os princípios pedagógicos que subjaziam, até então, às artes gramaticais latinas, aproximando dos estudantes o objeto de aprendizagem, por forma a melhorar as condições de ensino-aprendizagem nas aulas da lingua do Lácio. No contexto didático-gramatical português, Amaro de Roboredo, como é bem conhecido, parece ter sido o primeiro autor a adaptar de forma sistemática as suas obras de acordo com estes principios pedagógicos, habitualmente denominados sensualistas ou experimentalistas. Esta abordagem metodológica pode ser resumida na seguinte afirmação registada no prólogo ao Methodo grammatical para todas as linguas:

E das artes que nos retardão o uso devemos fugir com diligencia [...]. E como a mesma diligencia deve o Artifice, considerando o fim, \& os meios para chegar a esse fim, spicular a capacidade do que ha de usar desses meios, accomodandose aa natureza das suas potencias [...]. E como he notoria a grande dependencia, que o discurso humano tẽ dos sentidos corporaes, procede dereito dos effeitos para as causas, dos exemplos para aas regras (ROBOREDO, 2007 [1619], p. 19).

Ou, ainda no prólogo, mais adiante:

Fica logo clara a obrigação do Artifice quero dizer minha neste Methodo de me accommodar a rudeza pueril, screvendo na lingua Materna do principiante, levandoo per exemplos claros, \& ainda corporaes della para a Latina [...]. E fica clara a obrigação de dispor a materia ainda da lingua Materna segundo a natureza do discurso humano depẽdẽte dos sẽtidos [...]; ajuntando muitos exemplos em o livro, \& em voz, que o aprendiz veja, ouça, apalpe (ROBOREDO, 2007 [1619], p. 20).

Dos passos reproduzidos podem ser deduzidos dois critérios caraterizadores desta proposta didática: 1 . a preeminência da aprendizagem indutiva da língua objeto de estudo através das capacidades sensoriais - previsivelmente, por meio da compreensão auditiva e leitora - sobre o estudo dedutivo dos preceitos gramaticais, o que implica, por outro lado, que o aluno comece a interiorizar a estrutura gramatical através de amostras de língua que Roboredo, no fim do último passo apresentado, refere como sendo "exemplos em o livro, \& em voz, que o aprendiz veja, ouça, apalpe"; 2 . o uso obrigatório da língua materna do estudante como veículo para a aprendizagem da lingua latina (FERNANDES, 2002b, p. 467-485).

Neste contexto gramaticográfico, cabe situar outros autores que publicaram os seus manuais na primeira metade do século XVII, como é o caso da Arte de grammatica latina, nouamente ordenada em portuguez, pera menos trabalho 
dos que começão a aprender (Lisboa, 1636) do frade beneditino Frutuoso Pereira $(\dagger 1660)^{1}$, obra que teve duas outras edições (Lisboa, 1643 e 1652); na terceira, é apresentado um título diferente: Arte de grammatica, latina, portugueza, benedictina - pormenor este que poderá considerar-se um indício das alterações textuais registadas ao longo das edições da Arte. Sobre aspetos da teoria gramatical e da metodologia desta obra, bem como sobre questões que se prendem com a autoria, versa o presente trabalho.

\section{EM tORno dA AUTORIA DA ARTE DE GRAmmatica, LATINA, PORTUGUEZA, BENEDICTINA}

Antes de passar a analisar someramente os traços teóricos e pedagógicos principais da gramática de Frutuoso Pereira, parece-nos pertinente abordar de forma sucinta - embora, na verdade, se nos afigure bastante complexa - a questão da tradição textual desta obra. Um problema inicial - e de relevo - prende-se com a autoria, questão à qual se referem os bibliógrafos portugueses mais importantes. Por exemplo, Inocêncio da Silva (1883, t. X, p. 213) atribui a autoria da obra em estudo a João de Castelo Branco, bem como Diogo Barbosa Machado, o qual nos informa de que Castelo Branco publicou uma Arte de grammatica latina em Lisboa em 1636:

D. Ioão de Castellobranco natural de Lisboa onde foraõ seus illustres progenitores D. Duarte de Castellobranco primeiro Conde do Sabugal, e D. Catherina de Menezes filha de D. Bernardo Coutinho. Foy excellente Latino, e muito perito nos preceitos do idioma Romano. Ornado de summa prudência, e naõ menor vigilância exercitou o lugar de Prezidente do Senado de Lisboa em que o elegeo o Serenissimo Rey D. Ioão o IV. no anno de 1644. A sua caza era o refugio dos pobres, aos quais curava com ardente charidade ministrandolhe os medicamentos manipulados por suas próprias maõs. Falleceo em Lisboa com geral sentimento dos necessitados [...]. Compoz Arte de grammatica latina. Lisboa 1636. 4 (MACHADO, 1966 [1747], t. II, p. 626) ${ }^{2}$.

Frutuoso Pereira, por seu turno, terá apenas desempenhado o papel de editor nas duas primeiras edições da Arte; na terceira, Pereira teria passado a ser o autor, segundo se pode deduzir das palavras de Inocêncio da Silva:

A 1. ${ }^{\underline{a}}$ edição d'esta grammatica é de 1636; a 2. ํㅡㄹ 1643; e a seguinte de 1652, que se diz 3.-, é terceira certamente, contando sobre aquellas duas; mas parece que deve ser a primeira com respeito a fr. Fructuoso, que nas outras tinha sido

1 Uma notícia biobibliográfica do autor aparece na Bibliotheca Lusitana de Diogo Barbosa Machado: "Fr. Fructuoso Pereyra natural da Villa da Feira sinco leguas distante da Cidade do Porto, Cabeça de Condado, e descendente dos Condes deste Titulo, o qual querendo ser mais illustre por beneficio da Graça do que nacera por liberalidade da natureza recebeu a Cogulla Benedictina em o Convento da Cidade do Porto a 5 de Mayo de 1620. Foy muito douto nos preceitos da Gramatica Latina, Poesia heróica, e intelligencia das línguas Italiana Franceza, e Espanhola [...]. Falleceo no Mosteiro de S. Martinho do Couto a 20. de laneiro de 1660. Compoz. / Arte de Gramatica Latina novamente ordenada em Portuguez para menos trabalho dos que começaó a aprender. Lisboa por Lourenço Craesbeeck 1636. 4. Sahio segunda vez com este titulo. / Arte de Gramatica Latina ordenada em Portuguez para mayor facilidade deste estudo. Lisboa por Lourenço de Anveres. 1643. 8. Et ibi por Domingos Lopes Rosa. 1652. 8 [...]. / Faz memoria honorifica do Author Fr. Gregorio de Argaes Perla de Catalun. pag. 464. §. 156. Compuso el Arte de Gramatica que anda de baxo de su nombre com tan fácil disposicion para los principiantes, que hiziera escurecer todas las de mas artes desta materia si nó hubiera la oposición de la embidia, y del interés" (MACHADO, 1966 [1747], t. II, p. 305).

2 O fragmento reproduzido da Bibliotheca Lusitana parece ter sido a fonte de que Inocêncio da Silva se serviu para a notícia biobibliográfica correspondente: "filho do 1. Conde do Sabugal D. Duarte de Castello-branco, e Presidente do Senado da Camara de Lisboa, nomeado por el-rei D. João IV em 1644. - Foi natural de Lisboa, não constando comtudo a data do seu nascimento, nem tão pouco a do obito. - E. /618) Arte de Grammatica Latina. Lisboa, 1636. 4.” (SILVA, 1859, t. III, p. 344). 
mero editor, e n'esta foi auctor, porque refundiu a antecedente (SILVA, 1883, t. X, p. 213).

No que toca à autoria da Arte de grammatica, latina, portugueza, benedictina, depois de ter analisado e confrontado as três edições, parece-nos que Frutuoso Pereira não foi apenas editor da obra - no caso das duas primeiras edições -, mas autor, ou pelo menos não dispomos de dados consistentes para pensar que o autor da Arte em análise fosse João de Castelo Branco, pese embora a informação anteriormente referida por Barbosa Machado, quem, na notícia biobibliográfica correspondente a Pereira - parcialmente reproduzida na nota 1 do presente estudo -, afirma que o frade beneditino compôs uma Arte de grammatica latina, publicada, casualmente, no mesmo ano e local e até com o mesmo formato que aquela que é atribuída a João de Castelo Branco. Por outro lado, resulta esclarecedora - se bem que não determinante - a licença, datada de 12 de outubro de 1635, que aparece na primeira edição, na qual tão-só é mencionado o nome do frade beneditino. Seja como for, mesmo que atribuíssemos a João de Castelo Branco a autoria da obra, não podemos concordar com a afirmação de Inocêncio da Silva - apresentada no fim do fragmento anteriormente reproduzido -, segundo a qual Frutuoso Pereira, na terceira edição da gramática, poderia ser já considerado autor, porquanto "refundiu a antecedente". Na verdade, as alterações textuais ocorrem, segundo tivemos ocasião de comprovar, entre a primeira edição e as seguintes, e não entre a última e as duas anteriores, como Inocêncio da Silva sugere. Contudo, não obstante as profundas alterações estruturais e textuais detetadas do cotejo das três edições - muito especialmente, como acima referimos, entre a primeira edição e as duas restantes -, estamos perante uma obra, textual e conceitualmente, unitária.

\section{Princípios gRamaticais e metodológicos}

Partindo, por conseguinte, da consideração de que as três edições reproduzem, apesar das diferenças textuais, uma obra, cabe agora situar a Arte de grammatica, latina, portugueza, benedictina nas diversas tendências gramaticais e pedagógicas da altura, às quais se fez referência no início do presente estudo; ou, por outras palavras, cabe dilucidar em que medida se pode enquadrar Frutuoso Pereira nas propostas epistemológicas mais inovadoras na gramaticografia seiscentista, como é o caso do racionalismo e do sensualismo ou empirismo. No que se refere à incidência do empirismo, há já alguns anos sublinhamos (PONCE DE LEÓN, 1996, p. 224-226) o facto de haver, no manual de Pereira, uma profunda preocupação pela maneira como se aprendia a língua latina nas escolas portuguesas durante as primeiras décadas do século XVII. A este propósito, o frade beneditino tem clara consciência de que os critérios didáticos praticados nas aulas de Latim da época não eram os adequados, o que se mostra mais evidentemente logo no início do prólogo à terceira edição da gramática:

He a experiẽcia assistẽte antes cõpanheira da arte, os avisos daquella, saõ a firmeza dos documentos desta. O uso he hũa nova Arte que pode constituir a Arte natureza. Daqui nace, q̃ se com o tempo as Arte[s] se apuraõ, he porque o tempo se servio de experiencias no uso dellas. Muitos séculos há que se usa a Gramatica Latina, mas não foi com todo o uso das experiencias, q̃ cada dia o tempo prodúz, ou se serve. Naõ basta que tal artífice obrasse de tal sorte, pera q̃ cõ 
melhoras se naõ possa tirar novo modo de obrar do que se experimenta. O empyrico talves antes muitas vezes, obra com mais felicidade, q̃ o Methodico, \& $\tilde{q}$ o Racional, porq̃ se valeo mães do uso q̃ do preceito, mães da experiencia que da ciência, \& a empyrica naõ pode carecer de occultos preceitos, q̃ se os ignora o artifice pode constitu[i]llos no uso, porque nelle os observa.

Varios saõ os mestres antigos \& varios os modernos q̃ escreveraõ Gramàticas latinas, todos attenderão a todas as regras porã nem todos respeitão a todo uso. Não basta sò escrever bem, mas escrever tambẽ útil; \& a utilidade não respeita tanto ao preceito, como ao effeito. Estes são os que tocamos, os que admiramos. \& pella mayor parte nos não dà cuidado o inteiro conhecimento da causa: \& estas sempre ficão obscuras, senão chegão a produzir, em proporção hũ effeito de todo correlativo (PEREIRA, 1652, p. 6-7).

No passo reproduzido, o autor advoga de forma recorrente, no processo do ensino-aprendizagem da lingua latina - mas também, acrescentamos nós, no de outras linguas -, a preeminência da experiência - entendida esta como observação dos factos e que se pode indentificar também com o uso -, sobre a arte, ou conjunto de preceitos. Deste modo, o gramático - que Pereira, como outros gramáticos coevos, denomina de artífice -, ao adotar esta abordagem metodólogica, terá mais sucesso, no plano didático, que o normativista (methodico) ou o logicista (racional). Desta forma, Frutuoso Pereira parece distanciar-se tanto da gramática normativa, como da gramática racionalista. A adoção da abordagem experimentalista na Arte de grammatica, latina, portugueza, benedictina de Pereira deveria ter mais repercussões daquelas que, na verdade, são detetadas, se comparada com a Arte gramatical portuguesa, a nosso ver, mais representativa da corrente experimentalista; refiro-me à Grammatica latina de Amaro de Roboredo. Estas divergências, por exemplo, podem ser analisadas na exposição da matéria gramatical sobre o nome e o verbo, tal como aparece no seguinte Quadro 1.

Quadro 1 - O nome e o verbo em Roboredo (1625) e em Pereira (1636)

\begin{tabular}{|c|c|}
\hline Roboredo, 1625 & Pereira, 1636 \\
\hline $\begin{array}{l}\text { Fica mostrado que o No- } \\
\text { me he palabra, que tem } \\
\text { numeros, e Casos com } \\
\text { genero: e que se divide } \\
\text { em Substantivo, e Adjec- } \\
\text { tivo (p. 29). } \\
\text { Tem o Substantivo esta } \\
\text { propriedade, que pode } \\
\text { per si entrar na Oraçaõ } \\
\text { sem Adjectivo; e o Adjec- } \\
\text { tivo tem a contraria, que } \\
\text { naõ pode entrar na Ora- } \\
\text { çaõ sem ir junto ao Subs- } \\
\text { tantivo declarado, ou en- } \\
\text { tẽdido de fora (p. 30). }\end{array}$ & $\begin{array}{l}\text { O nome, he hũa parte da oração que se declina por casos, \& } \\
\text { naõ tem tempos. } \\
\text { O nome se diuide em Substantiuo, \& Adiectiuo. O Substan- } \\
\text { tiuo, he mais nobre que o Adiectiuo, porque significa per si a } \\
\text { cousa de que se trata na oração. } \\
\text { O Adiectiuo serue ao substantiuo, \& não pode estar na ora- } \\
\text { ção sem elle [...] (f. 1). }\end{array}$ \\
\hline
\end{tabular}


Quadro 1 - O nome e o verbo em Roboredo (1625) e em Pereira (1636) (continuação)

\begin{tabular}{|c|c|}
\hline Roboredo, 1625 & Pereira, 1636 \\
\hline $\begin{array}{l}\text { Fica mostrado nas Con- } \\
\text { jugações, que o Verbo he } \\
\text { hũa palabra que tem Nu- } \\
\text { meros, e Pessoas com } \\
\text { Tempo. E que ou he Acti- } \\
\text { vo; como. Amo, Amas; ou } \\
\text { Passivo; como Amor, } \\
\text { Amaris; e que cada hum } \\
\text { destes ou he Pessoal; co- } \\
\text { mo Amat, Amatur, ou he } \\
\text { Impessoal; como Amare, } \\
\text { Amavisse, Amari; Amã- } \\
\text { do, Amatũ, nos quaes se } \\
\text { encerrão os Tempos, Nu- } \\
\text { meros, e Pessoas (p. 67) }\end{array}$ & $\begin{array}{l}\text { A declinaçaõ do verbo se chama coniugaçaõ. E assi, overbo } \\
\text { he hũa parte da oraçaõ, que se declina, ou se coniuga por } \\
\text { modos, \& tem tempos } \\
\text { Os modos porque o verbo se coniuga saõ quatro, Indicatiuo, } \\
\text { Imperatiuo, Coniuntiuo, Infinitiuo. } \\
\text { Os tempos saõ seis. Tempo presente. Tempo passado im- } \\
\text { perfeito. Tempo passado perfeito. Tempo passado mais que } \\
\text { perfeito. Tempo que està para vir imperfeito. Tempo que es- } \\
\text { tà para vir mais que perfeito. } \\
\text { Diuidese o verbo, em pessoal, \& impessoal. O pessoal he } \\
\text { aquelle que tem todas as três pessoas, as quais saõ Ego,eu, } \\
\text { tu, tu, vos, ille, aquelle. O verbo impessoal he aquelle que } \\
\text { naõ tem mais que a terceira pessoa do singular, \& lhe faltaõ } \\
\text { as primeiras duas pessoas. } \\
\text { O verbo pessoal diuidese em actiuo, passiuo, neutro, } \\
\text { commũ, \& depoente. O verbo actiuo he aquelle, que acaban- } \\
\text { do na letra (o) se faz passiuo acrecentandolhe a letra ( } r \text { ) co- } \\
\text { mo, lego, eu leo, legor, eu sou lido. } \\
\text { O passiuo he aquelle que se forma do actiuo acredentando- } \\
\text { lhe a letra ( } r \text { ) como lego, legor. } \\
\text { O neutro he aquelle que acabando nas letras, m, ou, o, nun- } \\
\text { ca se faz passiuo, pessoal, como, sum, eu sou, sedeo, eu } \\
\text { estou assentado. } \\
\text { O commũ he aquelle, que acabando na silla, or, tem signifi- } \\
\text { cação actiua, \& também passiua, em algũs tempos, como } \\
\text { ao diante se verá. } \\
\text { O depoente he o que acabando na sillaba, or, tem significa- } \\
\text { çã actiua, ou neutra [...] (f. } 1 / \mathrm{r} \text { ). }\end{array}$ \\
\hline
\end{tabular}

Fonte: Elaborado pelo autor.

Com efeito, do confronto entre as duas obras pode concluir-se que, diferentemente da Grammatica de Roboredo, na Arte do frade beneditino não parece haver uma aplicação coerente dos princípios empíricos - à exceção do uso do Português como língua de redação da obra: na Grammatica roborediana, como o título da obra indica, os exemplos são apresentados antes dos preceitos, o que se pode deduzir, no Quadro 1, a partir das expressões como "fica mostrado" ou "mostra esta sentença" que iniciam os enunciados caraterizadores das partes da oração; Frutuoso Pereira, por sua vez, segue a sequência de exposição habitual na tradição gramatical latino-portuguesa, ao apresentar primeiro os preceitos e depois os exemplos. Não parecem, contudo, ser questões de método os únicos elementos que afastam a gramática de Frutuoso Pereira dos manuais roboredianos. No que diz respeito à teoria gramatical, encontramos nítidas divergências com a doutrina defendida por Roboredo ${ }^{3}$, com clara incidência na descrição das

3 Este critério parece-nos, no entanto, ser coerente com as propostas defendidas no prólogo da edição da Arte de gramatica de 
classes de palavras. Como é bem sabido, na esteira da gramática racional de Francisco Sánchez de las Brozas ${ }^{4}$ (SCHÄFER-PRIESS, 1990, p. 65-66; SCHÄFER-PRIESS, 2000, p. 135; PONCE DE LEÓN, 2002, p. 510; PONCE DE LEÓN, 2008, p. 246-247), Amaro de Roboredo propõe uma redução do número das partes da oração para cinco (nome, verbo, advérbio, conjunção e preposição) - se bem que na Grammatica latina sejam apenas caraterizadas as quatro primeiras por razões provavelmente de índole pedagógica. Por sua vez, Pereira segue a gramática latina tradicional na caraterização das partes da oração indeclináveis:

Quadro 2 - As partes da oração indeclináveis em Roboredo (1625) e em Pereira (1636)

\begin{tabular}{|c|c|}
\hline Roboredo, 1625 & Pereira, 1636 \\
\hline $\begin{array}{l}\text { Mostra [esta sentença] que o Adverbio he palavra } \\
\text { sem Numero, que altera a outra a que se ajunta. E } \\
\text { ajuntase principalmente a Verbos, e despois a Ad- } \\
\text { jectivos; e também a outros Advérbios [...]. } \\
\text { Mostra [esta sentença] que alg uas vezes se usa o } \\
\text { Adverbio em lugar de Nome (p. } 86 \text { ) }\end{array}$ & $\begin{array}{l}\text { O Aduerbio he parte da oraçaõ que } \\
\text { se naõ declina \& serue na oraçaõ, } \\
\text { pera declarar a força, \& modo da } \\
\text { significaçaõ do verbo, \& nome (f. } \\
\text { lr.). }\end{array}$ \\
\hline $\begin{array}{l}\text { Mostrão estas sentençãs, que a Conjunçaõ he pa- } \\
\text { lavra sem Numero que ajunta semelhantes casos, } \\
\text { tempos, e orações declaradas, ou entendidas de } \\
\text { fora per figura (p. 87). } \\
\text { Mostrase que sempre nas Orações precederá al- } \\
\text { g ua palavra a estas Conjunções [...]. } \\
\text { Mostra como sempre estas Conjunções se antepo- } \\
\text { rão a outra palabra que atão com a primeira [...]. } \\
\text { E notese que os Adverbios que ataõ se fazem Con- } \\
\text { junções (p. 133). }\end{array}$ & $\begin{array}{l}\text { A coniunçaõ he parte da oraçaõ } \\
\text { que se naõ declina, \& serue pera } \\
\text { atar, ou diuidir as partes da oraçaõ } \\
\text { (f. 1r.). }\end{array}$ \\
\hline & $\begin{array}{l}\text { O Pronome, he hrua parte da ora- } \\
\text { çaõ, que posta em lugar do nome } \\
\text { substantiuo, signfica certa \& de- } \\
\text { terminada pessoa (f. } 1 \text { ). }\end{array}$ \\
\hline----- & $\begin{array}{l}\text { O particípio he nome, que nace de } \\
\text { qualquer verbo, declinase por ca- } \\
\text { sos, \& significa tempo, \& assi h us } \\
\text { seruem pera tempo presente \& } \\
\text { passado, outros pera tempo futuro } \\
\text { (f. lr.). }\end{array}$ \\
\hline
\end{tabular}

(continua)

1652, que reproduzimos parcialmente acima e que parece oportuno aqui repetir: "O empyrico talves antes muitas vezes, obra com mais felicidade, q̃ o Methodico, \& ̃̃ o Racional, porq̃ se valeo mães do uso q̃ do preceito, mães da experiencia que da ciência, \& a empyrica naõ pode carecer de occultos preceitos, ̃̃ se os ignora o artifice pode constitu[i]llos no uso, porque nelle os observa" (PEREIRA, 1652, p. 6).

4 Pese embora as reservas iniciais, Carlos Assunção e Gonçalo Fernandes admitem, quanto ao número das partes da oração, que "indirecta e ideologicamente, o gramático português [i. e. Amaro de Roboredo] é influenciado pela Minerva de 1587 [do Brocense]" (FERNANDES; ASSUNÇÃO, 2007, p. Ivi). 
Quadro 2 - As partes da oração indeclináveis em Roboredo (1625) e em Pereira (1636) (conclusão)

\begin{tabular}{|c|c|}
\hline Roboredo, 1625 & Pereira, 1636 \\
\hline 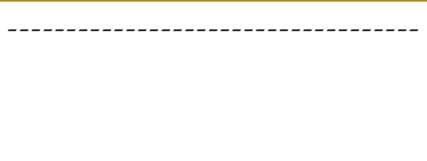 & $\begin{array}{l}\text { A praeposição he parte da oração que se não de- } \\
\text { clina, \& serue na oração, ou junta em composi- } \\
\text { çaõ de nome, \& verbo, ou apartada, \& então rege } \\
\text { caso depois de si (f } 1 . r) \text {. }\end{array}$ \\
\hline 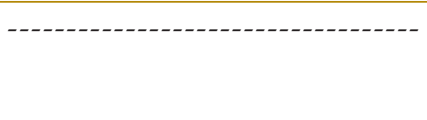 & $\begin{array}{l}\text { A interieição he parte da oração que se não de- } \\
\text { clina, \& serue pera declarar vários desejos \& af- } \\
\text { feitos do animo (f. 1r.) }\end{array}$ \\
\hline
\end{tabular}

Fonte: Elaborado pelo autor.

Há, por outro lado, diferenças nítidas entre Roboredo e Pereira na descrição gramatical de certas partes da oração - especialmente aquelas em que a matriz racionalista se torna mais evidente nas obras do primeiro autor -, como é o caso do verbo, que Roboredo $(1625$, p. 67) caracteriza como sendo " $h$ "ua palabra que tem Numeros, e Pessoas com Tempo". Nesta definição, Roboredo elimina o acidente do modo, como já analisámos num trabalho nosso anterior (PONCE DE LEÓN, 2008, p. 249-250), como traço caraterizador do verbo, o que, de novo, deve considerar-se influência da Minerva de Sánchez de las Brozas. Frutuoso Pereira, por seu turno, tal como se pode observar no Quadro 1, diferentemente de Roboredo, assume o modo como acidente verbal, estabelecendo um sistema quatripartido: indicativo, conjuntivo, imperativo e infinitivo. Em suma, pode verificar-se que, no plano teórico, a Arte de Frutuoso Pereira se distancia claramente da doutrina racionalista ${ }^{5}$.Nesse contexto, parece aparentemente simples responder à questão sobre o enquadramento teórico da Arte de grammatica, latina, portugueza, benedictina. Segundo o que vimos até agora, poderá afirmar-se que o frade beneditino segue a gramatica escolar latino-portuguesa; em concreto, os $D e$ institutione grammatica libri tres (Lisboa, 1572) do jesuíta Manuel Álvares, nomeadamente a edição que o também jesuita António Velez fez da gramática alvaresiana, publicada pela primeira vez em Évora, em 1599. Uma prova que pode ajudar a confirmar a nossa hipótese é, de novo, a descrição das classes de palavras:

Guadro 3 - As classes de palabras em Álvares / Velez (1599) e em Pereira (1636)

\begin{tabular}{|l|l|}
\hline Álvares / Velez, 1599 & Pereira, 1636 \\
\hline $\begin{array}{l}\text { Nomen est pars orationis, quae casus } \\
\text { habet, neque tempora adsignificat }\end{array}$ & $\begin{array}{l}\text { O nome, he hũa parte da oração que se declina } \\
\text { por casos, \& naõ tem tempos. } \\
\text { [...]. Substantiuum seu fixum nomen } \\
\text { est, quod per se in oratione esse po- } \\
\text { O nome se diuide em Substantiuo, \& Adiectiuo. } \\
\text { O Substantiuo, he mais nobre que o Adiectiuo, } \\
\text { seu appositum est, quod in oratione } \\
\text { esse non potest sine substantiuo } \\
\text { porque significa per si a cousa de que se trata na } \\
\text { oração. }\end{array}$ \\
O Adiectiuo serue ao substantiuo, \& não pode \\
estar na oração sem elle [...] (f. 1).
\end{tabular}

(continua)

5 A questão sobre a consideração do modo como acidente do verbo é apenas um elemento que ilustra as divergências entre a proposta de Frutuoso Pereira e os gramáticos racionalistas coevos, como Amaro de Roboredo; não é, com certeza, o único critério diferenciador: no Quadro 1, a respeito do verbo, pode observar-se que Pereira advoga a existência dos verbos impessoais ("O verbo impessoal he aquelle que naõ tem mais que a terceira pessoa do singular, \& Ihe faltaõ as primeiras duas pessoas" (PEREIRA, 1636 , f. 1)) ou a tipologia dos verbos em neutro, ativo, passivo, comum e depoente. Estas propostas, como é bem sabido, são rejeitadas pela doutrina logicista. 
Quadro 3 - As classes de palabras em Álvares / Velez (1599) e em Pereira (1636) (continuação)

\begin{tabular}{|c|c|}
\hline Álvares / Velez, 1599 & Pereira, 1636 \\
\hline $\begin{array}{l}\text { Verbum est pars orationis, quae mo- } \\
\text { dos et tempora habet, neque in casus } \\
\text { declinatur. Verbum duplex est, perso- } \\
\text { nale et impersonale. Personale est, } \\
\text { quod omnes personas utriusque nu- } \\
\text { meri habet [...]. Impersonale est, } \\
\text { quod prima et secunda utriusque nu- } \\
\text { meri et tertia multitudinis fere priva- } \\
\text { tur, unde et nomen traxit. Id duplex } \\
\text { est: alterum actiuae declinationis } \\
\text { [...]; alterum passiuae [...]. Verbum } \\
\text { personale diuiditur in quinque gene- } \\
\text { ra: actiuum, passiuum, neutrum, } \\
\text { commune, deponens. Actiuum est, } \\
\text { quod litera 'o' finitum passiuum fit } \\
\text { addita litera 'r' [...]. Passiuum est, } \\
\text { quod syllaba 'or' finitum actiuum fit } \\
\text { 'r' litera abiecta [...]. Neutrum est, } \\
\text { quod 'm' uel 'o' literis finitum ex se } \\
\text { passiuum personale non gignit (p. } \\
\text { 134). } \\
\text { Commune est, quod 'or' syllaba tan- } \\
\text { tum finitum actiui simul et passiui } \\
\text { significationem habet [...]. Deponens } \\
\text { est quod 'or' syllaba tantum finitum } \\
\text { actiui uel neutri significationem ha- } \\
\text { bet (p. 135). }\end{array}$ & $\begin{array}{l}\text { A declinaçaõ do verbo se chama coniugaçaõ. E } \\
\text { assi, overbo he h̃ua parte da oraçaõ, que se de- } \\
\text { clina, ou se coniuga por modos, \& tem tempos. } \\
\text { Os modos porque o verbo se coniuga saõ quatro, } \\
\text { Indicatiuo, Imperatiuo, Coniuntiuo, Infinitiuo. } \\
\text { Os tempos saõ seis. Tempo presente. Tempo } \\
\text { passado imperfeito. Tempo passado perfeito. } \\
\text { Tempo passado mais que perfeito. Tempo que } \\
\text { està para vir imperfeito. Tempo que està para vir } \\
\text { mais que perfeito. } \\
\text { Diuidese o verbo, em pessoal, \& impessoal. O } \\
\text { pessoal he aquelle que tem todas as três pes- } \\
\text { soas, as quais saõ Ego,eu, tu, tu, vos, ille, aquel- } \\
\text { le. O verbo impessoal he aquelle que naõ tem } \\
\text { mais que a terceira pessoa do singular, \& lhe fal- } \\
\text { taõ as primeiras duas pessoas. } \\
\text { O verbo pessoal diuidese em actiuo, passiuo, } \\
\text { neutro, comm u, \& depoente. O verbo actiuo he } \\
\text { aquelle, que acabando na letra (o) se faz passiuo } \\
\text { acrecentandolhe a letra (r) como, lego, eu leo, le- } \\
\text { gor, eu sou lido. } \\
\text { O passiuo he aquelle que se forma do actiuo } \\
\text { acredentandolhe a letra (r) como lego, legor. } \\
\text { O neutro he aquelle que acabando nas letras, m, } \\
\text { ou, o, nunca se faz passiuo, pessoal, como, sum, } \\
\text { eu sou, sedeo, eu estou assentado. } \\
\text { O comm u he aquelle, que acabando na silla, or, } \\
\text { tem significação actiua, \& também passiua, em } \\
\text { alg us tempos, como ao diante se verá. } \\
\text { O depoente he o que acabando na sillaba, or, tem } \\
\text { significaçã actiua, ou neutra [...] (f. } 1 / \text { r). }\end{array}$ \\
\hline $\begin{array}{l}\text { Pronomen est, quod loco nominis po- } \\
\text { situm certam finitamque personam } \\
\text { adsignificat (p. 132). }\end{array}$ & $\begin{array}{l}\text { O Pronome, he h̃ua parte da oraçaõ, que posta } \\
\text { em lugar do nome substantiuo, signfica certa \& } \\
\text { determinada pessoa (f. 1). }\end{array}$ \\
\hline $\begin{array}{l}\text { Participium est pars orationis, quae } \\
\text { tum casus, tum tempora habet ( } \mathrm{p} . \\
\text { 138). }\end{array}$ & $\begin{array}{l}\text { O particípio he nome, que nace de qualquer ver- } \\
\text { bo, declinase por casos, \& significa tempo, \& as- } \\
\text { si h us seruem pera tempo presente \& passado, } \\
\text { outros pera tempo futuro (f. } 1 \text { r.). }\end{array}$ \\
\hline $\begin{array}{l}\text { Praepositio est pars orationis, quae } \\
\text { ceteris partibus aut separata, aut } \\
\text { coiuncta fere praeponitur (p. 142). }\end{array}$ & $\begin{array}{l}\text { A praeposição he parte da oração que se não de- } \\
\text { clina, \& serue na oração, ou junta em composi- } \\
\text { çaõ de nome, \& verbo, ou apartada, \& então rego } \\
\text { caso depois de si (f } 1 . r) \text {. }\end{array}$ \\
\hline
\end{tabular}


Quadro 3 - As classes de palabras em Álvares / Velez (1599) e em Pereira (1636) (continuação)

\begin{tabular}{|l|l|}
\hline Álvares / Velez, 1599 & Pereira, 1636 \\
\hline $\begin{array}{l}\text { Aduerbium est pars orationis, quae } \\
\text { uocibus addita earum significatio- } \\
\text { nem explanat ac desinit (p. 144). }\end{array}$ & $\begin{array}{l}\text { O Aduerbio he parte da oraçaõ que se naõ decli- } \\
\text { na \& serue na oraçaõ, pera declarar a força, \& } \\
\text { modo da significaçaõ do verbo, \& nome (f. lr.). }\end{array}$ \\
\hline $\begin{array}{l}\text { Interiectio est pars orationis, quae } \\
\text { uarios animi affectus indicat (p. 145). }\end{array}$ & $\begin{array}{l}\text { A interieição he parte da oração que se não decli- } \\
\text { na, \& serue pera declarar vários desejos \& affei- } \\
\text { tos do animo (f. 1r.). }\end{array}$ \\
\hline $\begin{array}{l}\text { Coniunctio est pars orationis annec- } \\
\text { tens ordinansque sententiam (p. 146). }\end{array}$ & $\begin{array}{l}\text { A coniunçaõ he parte da oraçaõ que se naõ decli- } \\
\text { na, \& serue pera atar, ou diuidir as partes da } \\
\text { oraçaõ (f. 1r.). }\end{array}$ \\
\hline
\end{tabular}

Fonte: Elaborado pelo autor.

Do confronto entre a Arte de Frutuoso Pereira e a editio vellesiana da gramática de Manuel Álvares poder-se-á concluir que, a respeito de certas partes da oração, Pereira traduz ad litteram os preceitos alvarísticos. Seja como for, julgamos que não se deve considerar a gramática de Frutuoso Pereira como mais um dos numerosos cartapácios, utilizados pelos estudantes de Latim a partir de inícios de Setecentos, que vertiam para Português as regras da gramática de Manuel Álvares (PONCE DE LEÓN, 2001). De facto o próprio autor, no prólogo à edição de 1643, evidencia esta questão, ao denunciar que alguns críticos afirmavam que o manual em estudo não era senão um cartapácio da gramática alvaresiana:

Não faltarã emulos que a esta Arte quiserão dar titulo de Traslado, ou Cartapacio vulgar de Artes alheas (que nunca ao maldizente lhe faltou hum nome com que desautorizar o que inueja) já póde ser por sayr na primeira vez escrita em quarto mayor: \& assi se reduzio a menor, porque pareça Arte pello talhe. E se a caso foy, porque nella se achão Declinaçoens, Conjugaçoens, \& as mais partes, ou tratados necessarios da Grammatica; aução bastante, se for recebida terá o que primeiro compoz Arte de Grammatica Latina, pera queixarse dos que dipois delle escreuerão as suas, soo cõ prouar, que lhe vsurparão os Nominatiuos, as Conjugaçoẽs, \& as oito partes da Oração (PEREIRA, 1643, f. II3r).

A Arte de grammatica, latina, portugueza, benedictina de Frutuoso Pereira, com efeito, não parecer ser mais um dos materiais que, nas aulas de Latim no Portugal da primeira metade de Setecentos, comentavam e traduziam os preceitos alvarísticos, porquanto podem ser identificados, no manual em estudo, elementos que o afastam daqueles; por exemplo, o critério sistemático de redução da matéria gramatical, que obedece sem dúvida a critérios de índole pedagógica, mas que, na verdade, tem repercussões na descrição gramatical. A este respeito, pode, de novo, ser tomado como exemplo o estabelecimento do modo como acidente do verbo, que, segundo vimos, afasta a Arte de grammatica, latina, portugueza, benedictina da doutrina racionalista: o frade beneditino procede a uma redução do sistema modal, ao propor um sistema de quatro modos: "[...] os Verbos se conjugaõ por quatro modos. 1. Indicatiuo. 2. Imperativo. 3. Conjun- 
tiuo. 4. Infinitiuo" (PEREIRA, 1643, f. 44), perante a proposta multimodal defendida por Manuel Álvares, que divide o modo em indicativo, imperativo, conjuntivo, potencial, permissivo e infinitivo (SCHÄFER-PRIESS, 2010, p. 130-141; PONCE DE LEÓN, 2005, p. cxxviii-cxxxii). No entanto, pese embora a referida redução modal, a proposta da Arte de grammatica, latina, portugueza, benedicti$n a$ afigura-se-nos teoricamente mais avançada do que aquela registada nos $D e$ institutione grammatica libri tres, porquanto, no que toca ao conjuntivo, o gramático de Santa Maria da Feira alerta para a distinção entre o valor primário do modo e os sentidos decorrentes da combinação de certos advérbios e conjunções com as formas do conjuntivo:

Ha se de aduertir, que a lingoagem do Conjuntiuo, pella mayor parte, anda junta na Oraçaõ com algũ aduerbio, do qual he quasi regida, \& formada: ou com algũa Oração da qual depende em parte pera estar no Conjuntiuo. E basta que o tal aduerbio, ou Oraçaõ se entendão. E isto quer dizer Conjuntiuo. Lingoagem junta com algum aduerbio, ou acompanhada de outra Oração.

Do que se segue, que tantas species, ou modos de Conjuntiuos Regulares poderemos formar, quantas forem as diferenças dos Aduerbios, com que ajuntarmos a tal lingoagem.

Se a ajũtarmos cõ aduerbios de desejar, formaremos hum Conjuntiuo, que se chame Optatiuo.

Se com aduerbios aduersantes formaremos hum Subjuntiuo, que se chame. Aduersatiuo.

Se com Aduerbios negantes, formaremos. Subjuntiuo. Negatiuo.

Se com Aduerbios condicionais, formaremos, Conjuntiuo condicional, \& assi outros. E isto de tal sorte, que nunca as lingoagens do Conjuntiuo natural, \& regular se haõ de mudar, senão os Aduerbios (PEREIRA, 1643, f. 72/v).

No passo reproduzido, importa salientar a menção do "conjuntivo natural e regular". Se atentarmos no paradigma verbal, poderemos concluir que Frutuoso Pereira apresenta duas séries do conjuntivo: 1 . o conjuntivo (por exemplo, "amara eu agora" > Amarem) e 2. o segundo conjuntivo ou conjuntivo irregular (por exemplo, "como eu amo, ou amando eu agora" > Cum amem). Não há dúvida de que esta dupla distinção de "conjuntivos", aparentemente sem (muito) sentido, segue a proposta registada na gramática alvaresiana e cuja origem tem a ver com a forma - deficiente - como eram traduzidos para Português, na gramaticografia latino-portuguesa quinhentista, o conjuntivo latino introduzido pela conjunção cum - através do conjuntivo português: cum sim > "como eu seja" (!), em vez de "como eu sou" - e o introduzido por outras conjunções - através do conjuntivo português: quanuis sim > "embora eu seja". A consciência gramatical da divergência nas referidas traduções originou, a partir da edição de 1578 do manual alvaresiano, a introdução de duas séries do conjuntivo latino: 1. a primeira com formas de conjuntivo precedidas pela conjunção latina cum, mas com a tradução para Português através do indicativo; 2. a segunda com as formas próprias do conjuntivo - habitualmente precedidas pela conjunção quanuis e com a tradução através do conjuntivo português (PONCE DE LEÓN, no prelo).

Há, contudo, certo grau de divergência entre a Arte de grammatica, latina, portugueza, benedictina e a gramática do jesuita português, porquanto, apesar de registar o conjuntivo com formas de indicativo, Frutuoso Pereira tem consciência da anomalia gramatical que constitui este critério - relembre-se que o 
frade beneditino o designa como "conjuntivo irregular"; de facto, no prólogo alerta para a anomalia gramatical que supõe a inserção de formas do conjuntivo no paradigma do indicativo:

Dous Conjuntiuos se ordenarão; hũ q̃ chamamos Regular; outro Irregular, do que damos razaõ. O Conjuntivo he hum dos quatro modos perq̃ o Verbo se conjuga. Tomou esta denominaçaõ de q̃ sempre a Oraçaõ q̃ se ordena pello Conjũtiuo, ou anda junta, ou ajũta a sy outra oraçaõ, ou parte della, clara, ou entẽdida. Sirua de exẽplo. Eu escreuera agora. Esta lingoagẽ he do presente do Cõjuntiuo, \& suppoẽ, ou diz respeito a outra Oraçaõ que se lhe deue seguir. Como. Escreuera eu agora, se tiuera commodidade, \&.c. \& assi deuemos buscar lingoagẽs fixa, \& regulares, que sejaõ propriamente conjuntiuas.

E quando queiramos dizer que o Conjuntiuo se chama assi, porq̃ sempre a sua lingoagẽ traz cõsigo, ou pella mayor parte, algũ Aduerbio claro, ou occulto; tambem neste caso deuemos buscar hũa lingoagẽ fixa, com q̃ possamos ajuntar todos as Aduerbios. Seja exemplo. Tiuesse eu lido. he lingoagẽ do passado perfeito do Cõjuntiuo, ajũtandolhe hũ Aduerbio de desejar diremos: Oxalá: ou prouuesse a Deos q̃ tiuesse eu lido, \&.c. \& naõ assinando nòs esta lingoagẽ fixa, tãtos viraõ à ser os Conjuntiuos, ou modos delles, que fazem os Aduerbios. E daqui nacerão os Optatiuos, os Quanuis, \& outors, \&.

E o Conjuntiuo, que nestes nossos tẽpos se ensina cõ o Aduerbio - Cum - impropriamẽte se deue chamar; Porq a lingoagẽ Portuguesa que nelle vsamos, he do Indicatiuo, ajuntandolhe só o Aduerbio. Exẽplo. Eu leo. Como eu leo. E nẽ a lingoagẽ Portuguesa, nẽ a Latina q̃ neste Conjuntiuo se vsa, serue mais qu junta com o Aduerbio - Cum - \& assi não fica sendo Conjuntiuo Regular, porq̃ ouuera de ser géral, \& natural; pelo q̃ pomos em segundo lugar com titulo de Conjuntiuo Irregular, \& Improprio (PEREIRA, 1643, f. II7r/v).

\section{CONSIDERAÇões FINAIS}

Parece-nos conveniente salientar, na conclusão do presente trabalho, o valor da Arte de grammatica, latina, portugueza, benedictina, porquanto a sua publicação trata de ocupar o espaço pedagógico monopolizado pelos alvaresianos $D e$ institutione grammatica libri tres e pelo numerosos manuais (ou cartapácios) que traduziam para Português e comentavam os preceitos contidos naqueles. Para tal, Frutuoso Pereira serve-se, no plano pedagógico, das propostas mais inovadoras que se começaram a desenvolver no início do século XVII - como é o caso do sensualismo ou experimentalismo. Quanto à teoria gramatical, vimos que o frade beneditino se afasta da doutrina racionalista e, por consequência, de certos gramáticos como Amaro de Roboredo; mas, por outro lado, distancia-se também da gramática escolar vigente - os De institutione grammatica libri tres de Manuel Álvares - em certos aspetos como a redução da matéria gramatical. Estes traços peculiares levam-nos a pensar que estamos perante uma obra de notável interesse para a gramaticografia em Português.

\section{Notes about the Frutuoso Pereira's Arte de grammatica, latina, portugueza, BENEDICTINA (LISBON, 1636)}

Abstract: This paper analyzes several aspects of frutuoso Pereira's work Arte de gramatica, latina, portugueza, benedictina (Lisboa, 1636). Mainly issues that have 
to do with the textual tradition and authorship, as well as issues related to the Portuguese pedagogical context of the first half of the seventeenth century. It also analyzes the framing of the Arte de gramatica in the grammar current trends at the time, specifically, in the rationalist grammar and in the school grammar.

Keywords: Frutuoso Pereira. Grammatical historiography. XVII Century.

\section{REFERÊNCIAS}

ÁLVARES, M. Emanuelis Aluari e Socientate Iesu de institutione grammatica libri três Antonii Vellesii exe adem Societate Iesu in Eborensi Academia praefecti studiorum opera aucti et illustrati. Évora: Manuel de Lyra, 1599 [1572].

FERNANDES, G. Amaro de Roboredo, um pioneiro nos estudos linguísticos e na didáctica das línguas. 2002. Dissertação (Doutoramento)-Universidade de Trás-os-Montes e Alto Douro, Vila Real, 2002a.

FERNANDES, G. A primeira gramática latina escrita em Português. Revista Portuguesa de Humanidades, Braga, v. 6, fasc. 1-2, p. 481-495, 2002 b.

FERNANDES, G.; ASSUNÇÃO, C. Amaro de Roboredo, gramático e pedagogo português seiscentista, pioneiro na didáctica das linguas e nos estudos linguísticos. In: ROBOREDO, A. de. Methodo Grammatical para todas as Linguas. Edição fac-similada. Prefácio e Estudo Introdutório de Carlos Assunção e Gonçalo Fernandes. Vila Real: Centro de Estudos em Letras, Universidade de Trás-os-Montes e Alto Douro, 2007. p. xi-cii.

KOSSARIK, M. A doutrina linguística de Amaro de Roboredo. In: CASTRO, I. (Ed.). Actas do XII Encontro Nacional da Associação Portuguesa de Linguística. Lisboa: Associação Portuguesa de Linguística, 1997. v. II, p. 429-443.

MACHADO, D. B. Biblioteca Lusitana. Coimbra: Atlântida Editora, 1966 [1747]. t. II.

PEREIRA, F. Arte de grammatica latina, nouamente ordenada em portuguez, pera menos trabalho dos que começão a aprender. Lisboa: Lourenço Craessbeeck, 1636.

PEREIRA, F. Arte de grammatica latina, ordenada em portuguez, pera mayor facilidade deste estudo. 2. ed. Lisboa: Lourenço de Anveres, 1643.

PEREIRA, F. Arte de grammatica, latina, portugueza, benedictina. Lisboa: Domingos Lopes Rosa, 1652.

PONCE DE LEÓN, R. La pedagogía del latín en Portugal durante la primera mitad del siglo XVII. Cuadernos de Filología Clásica. Estudios latinos, Madrid, n. 10, p. 217-228, 1996.

PONCE DE LEÓN, R. El Álvarez en vernáculo: las exégesis de los De institutione grammatica libri tres en Portugal durante el siglo XVII. Revista da Faculdade de Letras da Universidade do Porto. Série Linguas e Literaturas, Porto, v. 28, p. 317-338, 2001.

PONCE DE LEÓN, R. O Brocense na teoría gramatical portuguesa no início do século XVII. Revista da Faculdade de Letras da Universidade do Porto. Série "Linguas e Literaturas, Porto, v. 29, p. 491-520, 2002.

PONCE DE LEÓN, R. Aproximación a la obra de Manuel Álvares. Edición crítica de sus De institutione grammatica libri tres. Madrid: Servicio de Publicaciones de la Universidad Complutense, 2005. 1 CD-ROM. 
PONCE DE LEÓN, R. Fuentes españolas en la primera gramática latina de Amaro de Roboredo. In: MARTÍNEZ GAVILÁN, M. D.; MAQUIEIRA, M. (Ed.). España y Portugal en la Tradición Gramatical. León: Universidad de León, Centro de Estudios Metodológicos e Interdisciplinares, 2008. p. 239-265.

PONCE DE LEÓN, R. Nótulas sobre as gramáticas latinas de Amaro de Roboredo: edições da mesma obra ou obras diferentes?. In: PEREIRA, B.; VÁRZEAS, M. (Ed.). As Artes de Prometeu: estudos em Homenagem a Ana Paula Quintela. Porto: Faculdade de Letras da Universidade do Porto, 2009. p. 135-148.

PONCE DE LEÓN, R. Contra las interferencias castellanas: en torno a la doble serie de formas del modo subjuntivo en la gramaticografia de la lengua portuguesa (siglos XVII y XVIII). Actes du XXVIIe Congrès international de linguistique et de philologie romanes (Nancy, 15-20 juillet 2013). Section 15: Histoire de la linguistique et de la philologie. No prelo.

PONCE DE LEÓN, R.; ASSUNÇÃO, C.; FERNANDES, G. A Arte de Grammatica de Pedro Sánchez. In: SÁNCHEZ, P. Arte de grammatica pera em breve saber latim. Edição facsimilada. Prefácio de Amadeu Torres e Estudo Introdutório de Rogelio Ponce de León, Carlos Assunção e Gonçalo Fernandes. Vila Real: Universidade de Trás-os-Montes e Alto Douro, Centro de Estudos em Letras, 2008. p. xi-xliii.

ROBOREDO, A. de. Methodo Grammatica para todas as Linguas. Edição fac-similada. Prefácio e Estudo Introdutório de Carlos Assunção e Gonçalo Fernandes. Vila Real: Centro de Estudos em Letras, Universidade de Trás-os-Montes e Alto Douro, 2007 [1619].

ROBOREDO, A. de. Grammatica latina. Mais breue, e fácil que as publicadas até agora na qual precedem os exemplos aas regras. Lisboa: António Alvarez, 1625. SCHÄFER-PRIESS, B. Amaro de Roboredos Methodo gramatical para todas as linguas (1619). In: CAETANO DA ROSA, L.; SCHÖNBERGER, A.; SCOTTI-ROSIN, M. (Org.). Zur Wissenschaftsgeschichte Lusitanistik. Akten des 1. Gemeinsamen Kolloquiums der deutschsprachigen Lusitanistik und Katalanistik (Berlin, 20. - 23. September 1990). Frankfurt am Main: TFM, Domus Editoria Europaea, 1990. p. 55-74.

SCHÄFER-PRIESS, B. Die portugiesische Grammatikschreibung von 1540 bis 1822. Entstehungsbedingungen und Kategorisierungsverfahren von dem Hintergrund der lateinischen, spanischen und französischen Tradition. Tübingen: Max Niemeyer, 2000.

SCHÄFER-PRIESS, B. Os modos verbais nas gramáticas latino-portuguesas de Manuel Álvares (1572) e Bento Pereira (1672). Revista de Letras, Vila Real, II, v. 9, p. 121-153, 2010.

SILVA, I. da. Diccionario Bibliographico Portuguez. Lisboa: Imprensa Nacional, 1859, t. III; 1883, t. X. 